\title{
DIABETIC CONTROL VIA FUZZY SYSTEMS
}

\author{
R. C. Diniz ${ }^{1}$, G. L. O. Serra ${ }^{2}$
}

${ }^{1}$ Department of Pharmacy, Federal University of Maranhao (correspondingroseanecd@gmail.com)

${ }^{2}$ Department of Electrical and Electronics, Computational Intelligence Laboratory of Applied Technology, Federal Institute of Education, Science and Technology of Maranhao (ginalber@ifma.edu.br)

\begin{abstract}
Diabetes is one of the most serious public health problems of today. According to the IDF (International Diabetes Federation) in a study published recently, Brazil currently occupies the 5th place in the world list of nations with the largest number of sufferers [1].

A fuzzy controller in the context of diabetes plays the role of deciding the amount of insulin needed to keep the body functioning, since the pancreas is not performing its function properly. The main advantage of using fuzzy control systems is based on the fact that the mathematical equations are not able to correctly simulate a biological system, because the parameters of system are enough variables because they are open thermodynamic systems, which have factors internals and externals interference [2].

For better analysis of the control system based on fuzzy logic, we used the clinical data available from the University of California at San Diego in the Project Monitoring and Control Glucose in Humans. In the control plant was used as a dynamic model of the patient actual data and not a mathematical model that represents a biological system [3].

In this manner can be analyzed the efficiency of a fuzzy controller made from an artificial model (a set of mathematical equations) for the glucose-insulin system and the sensitivity level of control compared to Chein and Tsai 2010 [4].
\end{abstract}

The results satisfactorily met the goal in question, in other words, to keep the rate glucose in physiologically normal level using data from clinical patients of Project Monitoring Glycemic Control and the University of San Diego through a fuzzy controller made from a model mathematical for glucose-insulin system.

Keywords: Glucose-Insulin System, Diabetes, Fuzzy Control. 


\section{INTRODUCTION}

A fuzzy system is a dynamic mapping between its non-linear input variables and output. The inputs and outputs are real numbers and fuzzification interface converts numeric entries in fuzzy sets, the inference engine uses the rule base to produce conclusions and defuzzification interface converts the findings into numerical outputs.

A fuzzy controller in the context of diabetes plays the role of deciding the amount of insulin needed to keep the body functioning as it is known as the pancreas is not performing its function properly [5].

\section{FUZZY CONTROL IN DIABETES}

This control is based on a fuzzy input representing an error value derived from the value of glucose concentration in a given time to a value of glucose concentration reference. This error value as input the controller is designed in a Cartesian plane with degrees of membership functions by Gaussian. The set of fuzzy rules relating the amount of error due to the concentration of insulin is the controller output at the same time as the match input of the mathematical model which represents a patient with diabetes. The membership function for this control was adopted gaussmf because as observed clinical data demonstrate a pattern of oscillatory behavior for the biological system (see equation 1 and figure 1) [5] and [6].

$$
f(x ; \sigma, c)=e^{\frac{-\left(x-c^{2}\right.}{2 o^{2}}}
$$
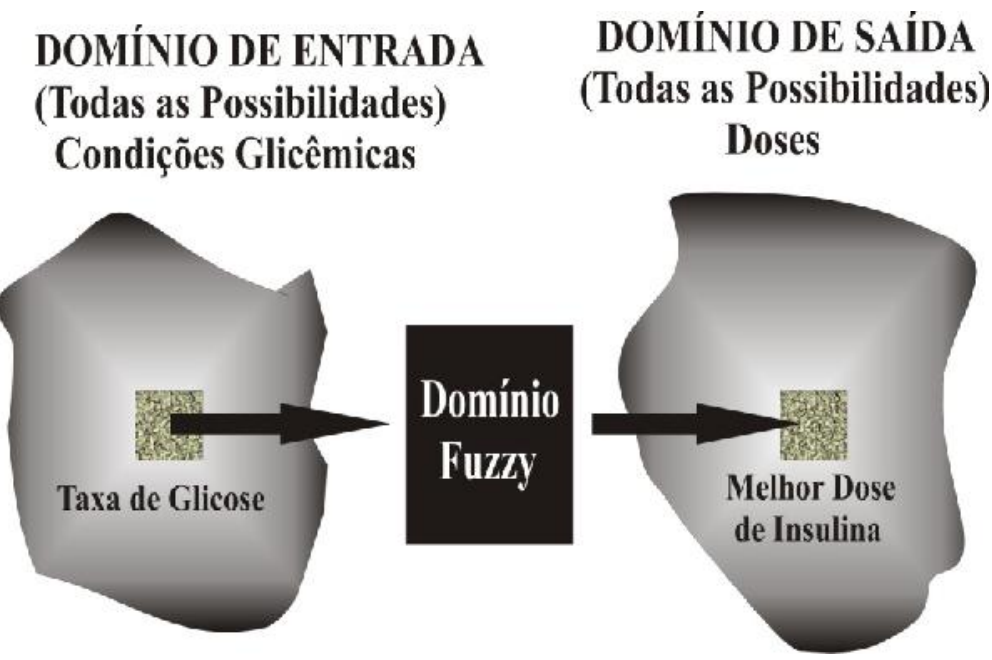

Figure 1. Mapping between input variables and output a fuzzy controller.

The figures (2-4) show the data obtained for the fuzzy control of individuals in Table 1. 
Table1. Individual characteristics of subjects. (see [3])

\begin{tabular}{cc}
\hline Subject & Condition \\
\hline (simnorm) & Normal \\
(sanpregone6) & Type I Diabetes \\
(pfeniddm1) & Type II Diabetes \\
\hline
\end{tabular}
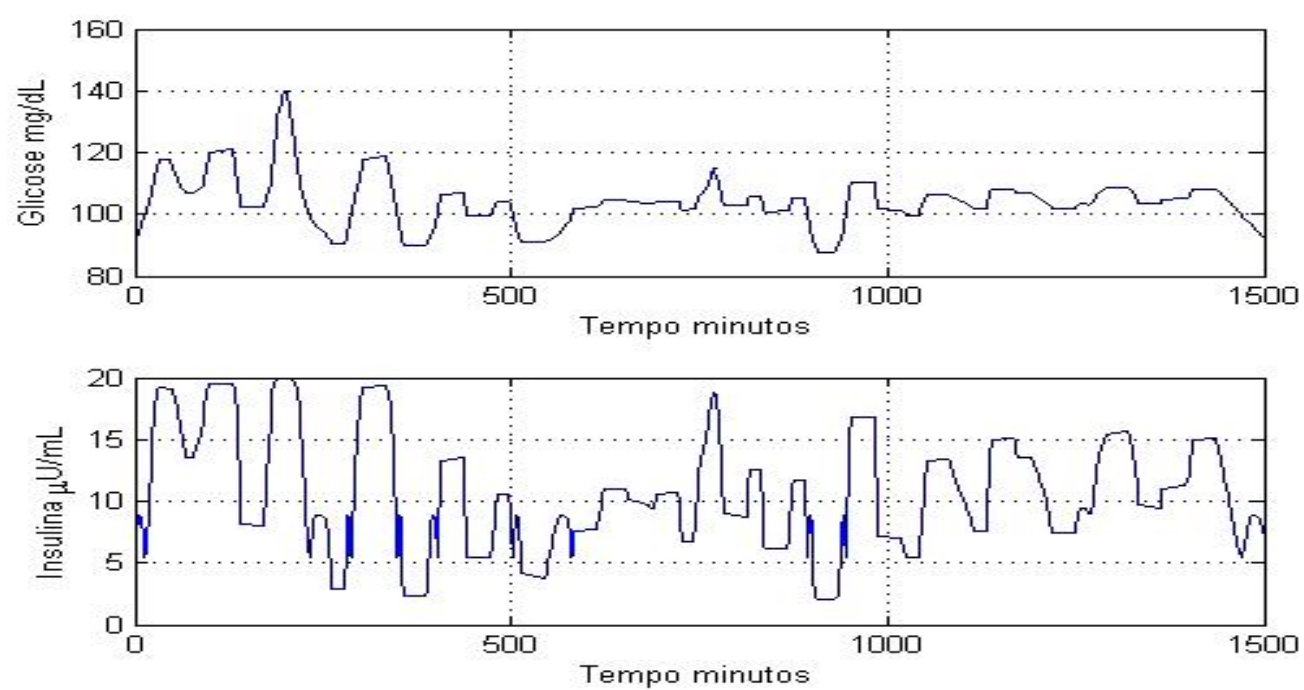

Figure 2. Graph showing the behavior of insulin in the course of the simulation for normal individuals.
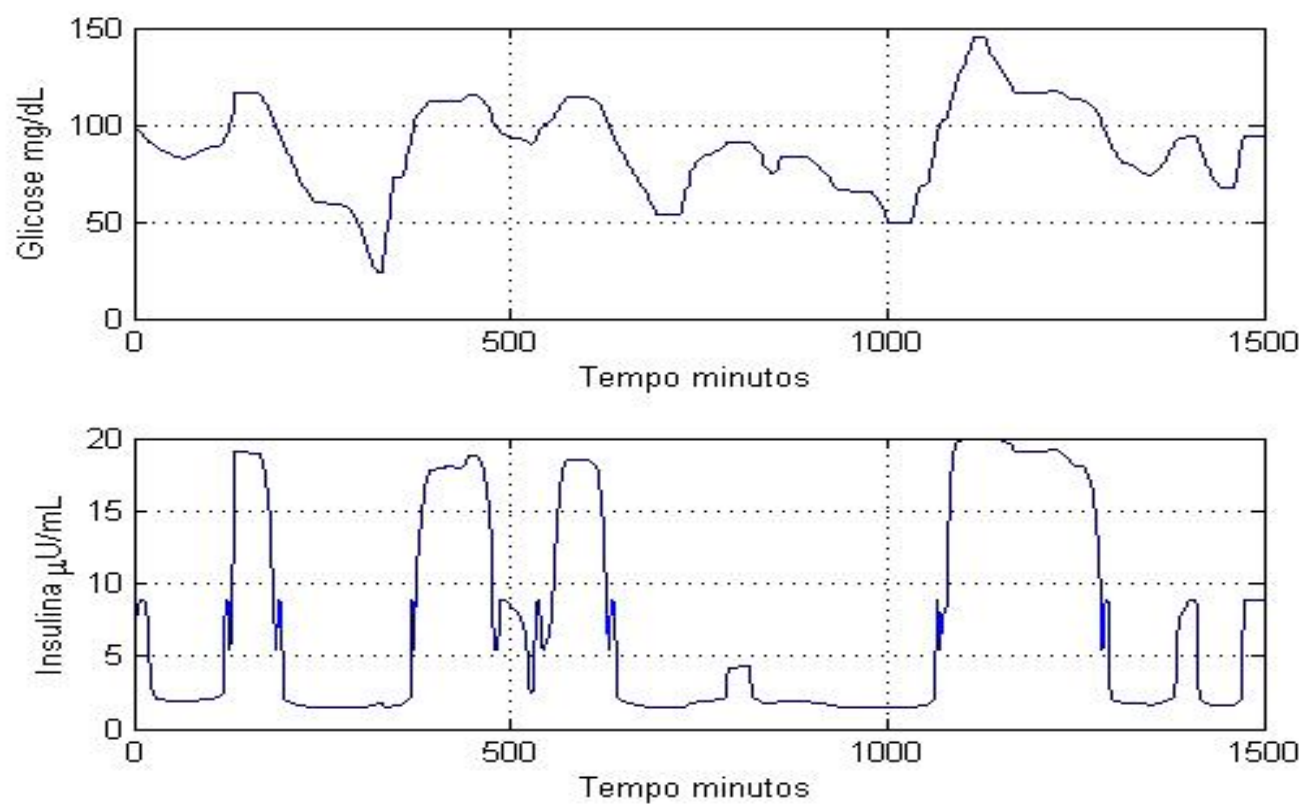

Figure 3. Graph showing the behavior of insulin in the course of the simulation for individuals with Type I Diabetes. 

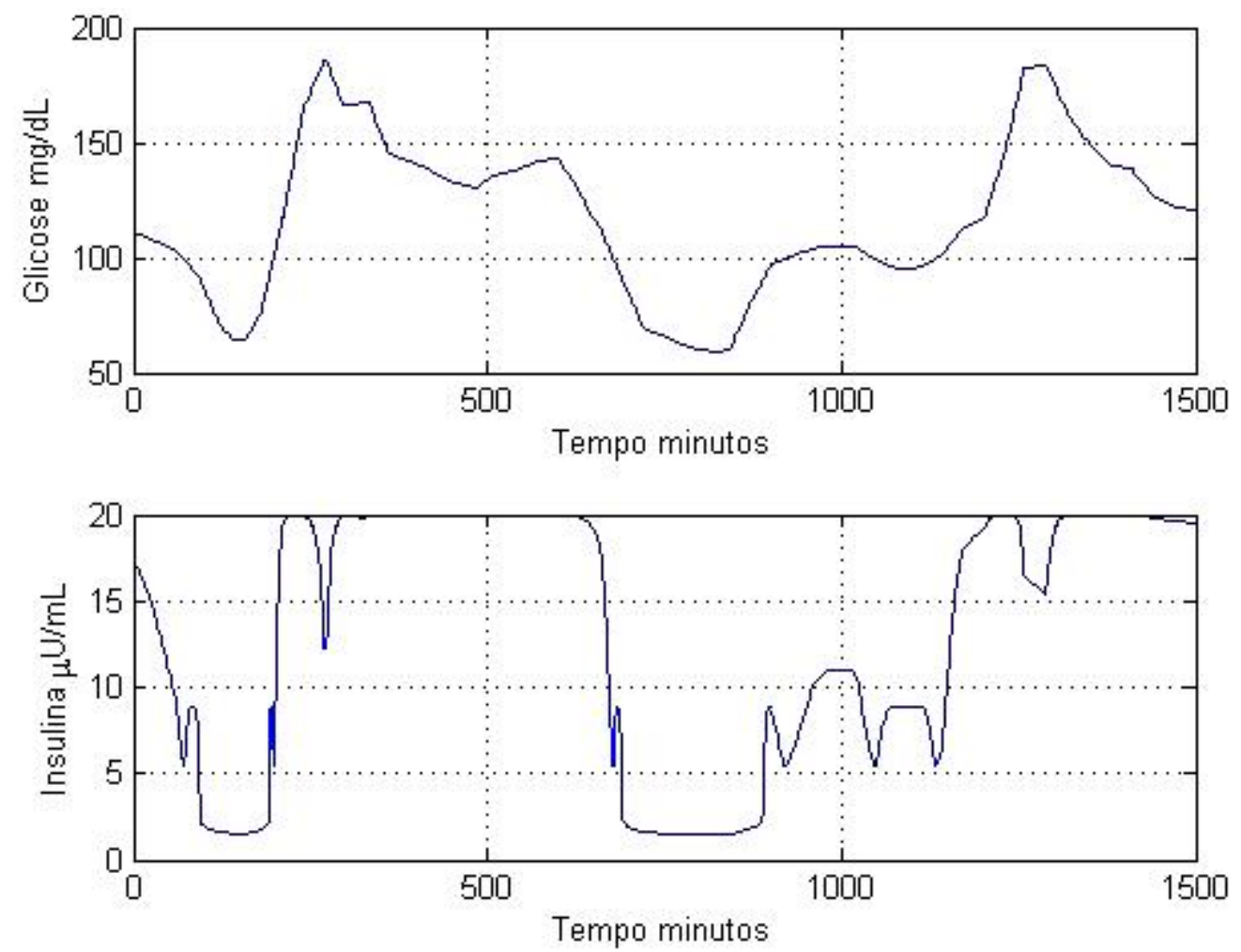

Figure 4. Graph showing the behavior of insulin in the course of the simulation for individuals with Type II Diabetes.

\subsection{Conclusion}

Using the mathematical model which simulates the behavior of a normal individual and from an individual in pathological conditions has been proposed a fuzzy control system to regulate glucose levels in this case where there is a computer model that represents an individual with diabetes. The results demonstrate the efficiency of the fuzzy controller, as it had served the purpose in question, in other words, to keep the rate physiologically normal glucose levels.

\section{Acknowledgements}

This work is the result of a joint effort of the Foundation of Research and Scientific and Technological Development of Maranhao, Federal Institute of Education, Science and Technology of Maranhao and all colleagues of the scientific community at the Federal University of Maranhao. 


\section{REFERENCES}

[1] Brown, L., Edelman, E. R. Optimal Control of Blood Glucose: The Diabetic Patient or the Machine?, Science Translational Medicine, 27 (2010), 559 - 573.

[2] MAKROGLOU,Athena; LI, Jiaxu; KUANG, Yang. Mathematical models and software tools for the glucose-insulin regulatory system and diabetes: na overview. Applied Numerical Mathematics 56, 2006. 559-573 p.

[3] Searched: http://glucosecontrol.ucsd.edu/data.html. Acesso em 01.11.11.

[4] Chen, C. L., Tsai, H. W. Modeling the physiological glucose-insulin system on normal and diabetic subjects, Computer Methods and Programs in Biomedicine, 97 (2010), 130 140.

[5] Wang. A Course in Fuzzy Systems and Control. Prentice Hall, 1996.

[6] Cecil, Russel L., Tratado de Medicina Interna. 2a Edição. Rio de Janeiro: ELSEVIER, (2005). 